\title{
Sobre la planta hospedera de Cercophana frauenfeldii (Felder) (Lepidoptera: Saturniidae) en Magallanes
}

\author{
About the host plant of Cercophana frauenfeldii (Felder) \\ (Lepidoptera: Saturniidae) in Magallanes
}

Álvaro Zúñiga-Reinoso ${ }^{1}$ \& Joaquín Sepúlveda ${ }^{2}$

Históricamente se ha registrado a Cercophana frauenfeldii (Felder, 1982) como parte de la entomofauna de la Región de Magallanes (Mabille, 1891). Sin embargo, en la región existen apenas dos registros de adultos en la zona archipelágica australes de Isla Hoste y Cabo de Hornos (Pérez, 2002). Hasta la fecha se han descrito tanto el macho como la hembra en estado adulto (Ureta, 1944; Artigas, 1994; Angulo et al. 2004), capullo (Jordan, 1924) y la larva de ultimo instar (Butler, 1882; BarlettCalvert, 1894; Ureta, 1944; Artigas, 1994). Sin embargo, antecedentes acerca del huevo, pupa y número de instares larvales no se han documentado. Por otra parte, sobre la fenología de esta especie se ha establecido que el período de vuelo de los adultos comprende los meses de febrero a junio (Angulo et al. 2004; Rebolledo et al. 2006). No obstante, la información acerca de las plantas hospederas donde se desarrolla la larva es escasa. Con respecto a lo anterior, BarlettCalvert (1894) registra al peumo (Cryptocaria alba (Molina) Looser: Lauraceae) como hospedero para la especie y posteriormente Artigas (1994) menciona que es posible encontrar larvas de C. frauenfeldii defoliando paltos (Persea americana Miller: Lauraceae), información que es ratificada en el catálogo de Angulo et al. (2004). Existe referencia de que Barlett-Calvert (1894), menciona como nota del traductor haber encontrado la larva y los capullos en el "belloto" en la hacienda San Isidro, Quillota en el año 1885. Suponemos, por distribución geográfica de la especie, que Barlett-Calvert (1894) se refería al belloto del norte (Beilschmiedia miersii (Gay) Kosterm: Lauraceae) como especie mesonera, pero esta relación trófica no ha sido verificada posteriormente.

Actualmente, no han habido nuevos registros en la región y nada se conoce sobre la biología de este insecto en la zona, dato curioso ya que ninguna de las dos plantas hospederas documentadas para la especies, ambas de la familia Lauraceae, están presentes en Magallanes. Por lo tanto, el objetivo de esta nota es reportar la planta hospedera de Cercophana frauenfeldii en la región de Magallanes, así como también entregar un nuevo registro regional por medio de un estado inmaduro.

El material fotográfico revisado corresponde a uno de los dos individuos observados por el primer autor, con el siguiente dato: Antártica Chilena, Cabo de Hornos, Puerto Williams, Parque Etnobotánico Omora. Febrero de 2003. Alimentándose de hojas Drymis winteri J. R. Forst. \& G. Forst (Winteraceae) (Fig. 1).

Este es el primer registro de $D$. winteri (Winteraceae) como planta hospedera de $C$. frauenfeldii y es el primer registro de los estados inmaduros de esta especie en la región

\footnotetext{
1 Laboratorio de Genética y Evolución, Departamento de Ciencias Ecológicas, Facultad de Ciencias, Universidad de Chile, Las Palmeras 3425, Santiago, Chile.

$\gg$ alzure@gmail.com

2 Pasaje 6, \#2120. Población el Boldo II, Curicó, Chile.
} 


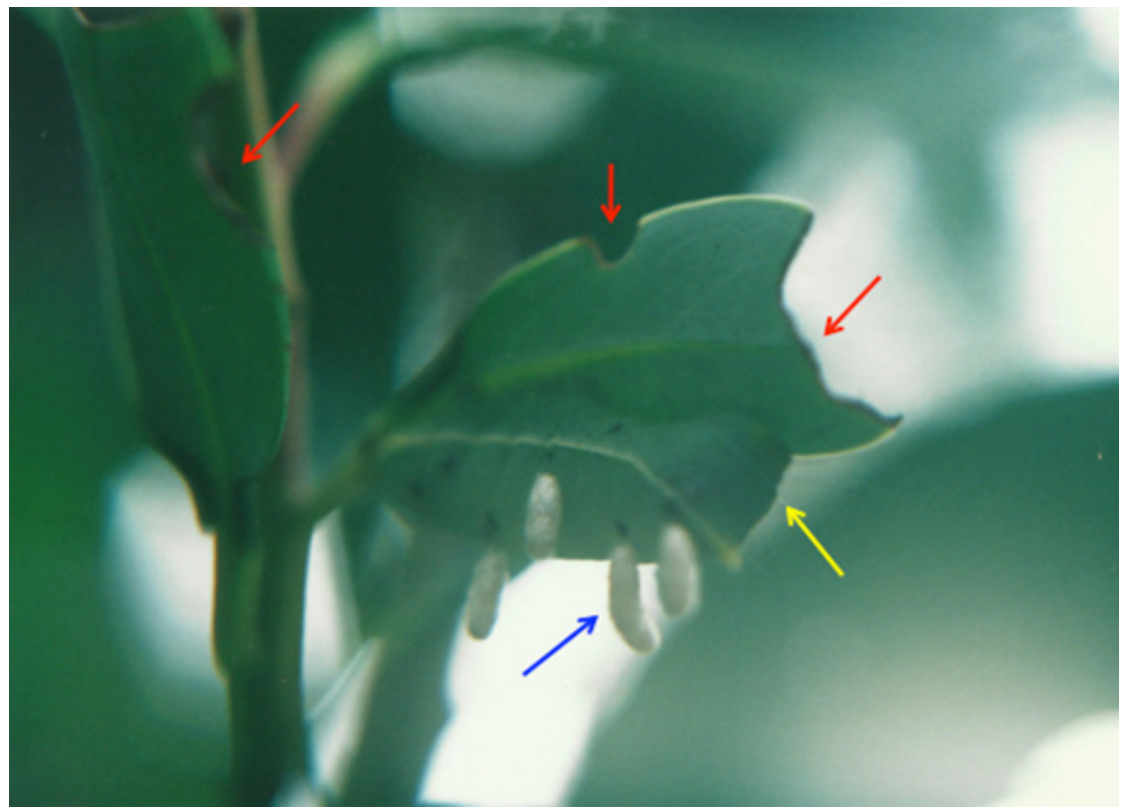

Fig. 1. Reporte fotográfico del estado inmaduro de Cercophana frauenfeldii sobre Drymis winteri. La flecha amarilla indica la sección cefálica oculta en los primeros dos segmentos torácicos, posición típica de reposo de la larva de C. frauenfeldii . Flechas rojas indican marcas de consumo de las hojas de D. winteri. Flecha azul indica pupas colgantes de parasitoides no identificados.

de Magallanes. Esto permite fundamentar biológicamente la presencia de $C$. frauenfeldii en la región de Magallanes, debido a que esta especie puede hacer todo su ciclo de vida en esta región austral mediada por la presencia de una planta hospedera. La larva de último instar de esta especie puede reconocerse por poseer un scoli amarillo (i.e cuerno verrucoso) en el tercer segmento, orientado hacia delante y portar setas largas, de color negro que terminan en un engrosamiento apical que le da un aspecto de porra (ver en Fig. 1). También se pueden reconocer porque debajo de los espiráculos de ambos lados del cuerpo, nace una línea lateral salpicada de verrugas amarillentas que se origina en el pico del scoli y termina en una punta aguda en el escudo anal. Sin embargo, puede ser fácilmente confundida con la otra especie del género Cercophana presente en Chile, la Cercophana venusta (Walker, 1856). No obstante las larvas de C. venusta no portan setas largas ni engrosadas en el ápice; estas presentan ocho bandas blancas, dispuestas de forma oblicua, que nacen en la zona mediodorsal y terminan próximas a los espiráculos (Wolfe \&
Balcázar-Lara, 1994). Adicionalmente, no existen registros a la fecha de la presencia de $C$. venusta en la región de Magallanes (Angulo et al. 2004), por lo que $C$. frauenfeldii sería el saturnido mas austral del mundo (Nuñez, 2015). Cabe destacar, que el ejemplar fotografiado presenta signos de ataque de parasitoides, sin conocer a que especie corresponde. La única especie de parasitoide reportada para $C$. frauenfeldii es la especie Perissocentrus chilensis Crawford 1910 (Hymenoptera: Torymidae) (Grisell, 1992). Sin embargo, este tipo de ataque corresponde a otra familia de himenópteros parasitoides, el cual debe ser confirmado. Posiblemente se trate de una especie de Braconidae, ya que estos cuando se encuentran en fase de pupa, hacen sus capullos colgantes con forma de grano de arroz. Finalmente, reportes como este permiten conocer la biología de las especies presentes en la región.

\section{AGRADECIMIENTOS}

Quisiéramos agradecer al Dr. Ricardo Rozzi y a la Dra. Francisca Massardo por la 
invitación a muestrear entomofauna en el Parque Etnobotánico Omora que permitió este interesante registro. Además agradecer a los aportes desinteresados de los revisores anónimos.

\section{LITERATURA CITADA}

Angulo, A., Lemaire, C., \& Olivares, T. (2004). Catálogo crítico e ilustrado de las especies de la familia Saturniidae en Chile (Lepidoptera: Saturniidae). Gayana, 68(1), 20-42.

Artigas, J. N. (1994). Entomología Económica. Insectos de interés agrícola, forestal, médico y veterinario (nativos, introducidos y susceptibles de ser introducidos) ( $1^{\mathrm{a}}$ edn.). Concepción, Chile: Editorial Universidad de Concepción.

Barlett-Calvert, W. (1894). Nuevos Lepidópteros de Chile. Anales Universidad de Chile. Memoria Científica, 87, 133-182.

Butler, A. (1882). Additional notes on Bombyces collected in Chili by Mr. Edmonds. Transactions of the Royal Entomological Society of London, 30, 101-108.

Grisell, E. E. (1992). A revision of Perissocentrus Crowford (Hymenoptera: Torymidae).
Journal of Hymenoptera Research, 1, 91-102.

Jordan, K. (1924). On the saturnoidean families Oxytenidae and Cercophanidae. Novitates Zoologicae, 31, 135-193, pl. 6-21.

Mabille, M. P. (1891) Lépidopteres. En: Mission Scientifique du Cap Horn 1882-1883. Tome VI. Zoologie. 10 (pp. 3-35, pls. I-III). Paris: Ministéres de la Marine et de 1 'Instruction Publique.

Núñez, E. (2015). Catálogo preliminar de Saturniidae de Argentina, con veintiun nuevos registros (Lepidoptera: Saturniidae). Tropical Lepidoptera, 25,22-33.

Pérez, V. (2002). Sobre Cercophana frauenfeldi Felder (Lepidoptera: Cercophanidae) en la región de Magallanes. Anales del Instituto de la Patagonia, 30, 113-116.

Ureta, E. (1944). La familia Saturniidae (Heterocera) en Chile. III parte. Boletín del Museo Nacional de Historia Natural, 22, 49-64.

Wolfe, K., \& Balcázar-Lara, M. (1994). Chile's Cercophana venusta and it's inmature stages (Lepidoptera: Cercophanidae). Tropical Lepidoptera, 5(1), 35-42. 
